\title{
Article
}

\section{Two new species of aphyllophoroid fungi (Basidiomycota) from southern China}

\author{
Fu-Chang Huang ${ }^{1,2}$, Bin $\mathrm{Liu}^{2 *}$, Hao $\mathrm{Wu}^{2}$, Yuan-Yuan Shao ${ }^{2}$, Pei-Sheng Qin ${ }^{2}$, \\ Jin-Feng $\mathbf{L i}^{2}$
}

${ }^{1}$ College of Life Science and Technology, Guangxi University, Nanning, 530005, China

${ }^{2}$ Institute of Applied Microbiology, College of Agriculture, Guangxi University, Nanning, 530005, China

Huang FC, Liu B, Wu H, Shao YY, Qin PS, Li JF 2017 -Two new species of aphyllophoroid fungi (Basidiomycota) from southern China. Mycosphere 8(6), 1270-1282, Doi $10.5943 /$ mycosphere $/ 8 / 6 / 12$

\begin{abstract}
Two new species of aphyllophoroid fungi (Basidiomycota) from Nonggang, Guangxi Autonomous Region, tropical, China are described. Perenniporia nonggangensis mainly characterized by resupinate to effused-reflexed basidiocarps with cream to greyish cream pore surface, up to $1.4 \mathrm{~cm}$ thick, broad-ellipsoid to subglobose, non-truncate and non-dextrinoid basidiospores. Aporpium obtusisporum characterized by pileate basidiocarps with poroid to lamellate hymenophore when mature, abundant hyphal pegs on both pileal surface and tubes, ovalelliptic, obtuse apically, cyanophilous basidiospores. Morphology and sequence analysis of the combined ITS and nLSU dataset support their taxonomic position as new species.
\end{abstract}

Key words -Morphological structure - Phylogeny - Polyporaceae - Aporpiaceae - Taxonomy

\section{Introduction}

Nonggang Natural Reserve is located in the Sino-Vietnam border region of southern China. The data of the biodiversity of aphyllophoroid fungi in the reserve are limited, only very few species were reported from the reserve (Yuan \& Dai 2012). During an inventory on macrofungal diversity in the reserve, several interesting polypore collections were encountered. Perenniporia and Aporpium are the possible genera for these collections.

The genus Perenniporia Murrill was typified by Polyporus medulla-panis Jacq. (Donk 1960), and it is characterized by the ellipsoid to distinctly truncate basidiospores, which are usually thickwalled and have a variable dextrinoid reaction; hyphal system is dimitic to trimitic with clamp connections on generative hyphae, vegetative hyphae are cyanophilous and variably dextrinoid (Decock \& Stalpers 2006, Zhao et al. 2013a). Species in Perenniporia are lignicolous and cause a white rot, growing on living or dead hardwoods and conifers. Until now, about one hundred species have been described or transferred to the genus (Cui \& Zhao 2012, http://www.indexfungorum.org/names/Names.asp), out of those 49 species were recorded from China (Zhao et al. 2014), and recent two new species were reported in 2015 (Decock \& Ryvarden 2015, Jang et al. 2015).

The genus Aporpium Bondartsev \& Singer was typified by Aporpium canescens (P. Karst.) Bondartsev \& Singer $[=$ A. caryae (Schwein.) Teixeira \& D.P. Rogers], and redefined by Sotome et al. (2014) recently, it is characterized by resupinate to sessile basidiocarps, fleshy to leathery 
context, poroid hymenophore, a dimitic hyphal systems with unbranched skeletal hyphae, clavate or ovate to pyriform probasidia, and ellipsoid to cylindrical or allantoid basidiospores (Singer 1944, Sotome et al. 2014). The other relate genera viz. Elmerina, Protodaedalea and Protomerulius have also been described to accommodate polypores with septate basidia, and they have been variably used in the literature by different authors (Ryvarden 1991, Núñez \& Ryvarden 2001). Reid (1992) considered Aporpium to be a synonym of Elmerina. Ryvarden (1991) also treated Aporpium as a synonym of Protomerulius, which typified by Protomerulius brasiliensis and was characterized by resupinate basidiocarps with poroid hymenophore, a dimitic hyphal system, and ovate to pyriform and cruciate epibasidia. Miettinen et al. (2012) treated Aporpium as an independent genus distinct from Elmerina and Protomerulius. Sotome et al. (2014) redefined the concept of Aporpium based on the phylogenetic analyses, and they retained Elmerina separate from Aporpium and Protodaedalea since the phylogenetic position of E. cladophora was not yet clear. Wu et al. (2017) accepted the concept of the genus Aporpium given by Sotome et al. (2014), and added a new species to the genus recently.

During our recent study on macrofungal diversity in southern China, two additional undescribed species of Perenniporia and Aporpium were found, they were confirmed as new by their special morphological characteristics and the phylogenetic analyses of the combined sequences dataset from internal transcribed spacer (ITS) region and nuclear large subunit ribosomal DNA (nLSU) region.

\section{Materials \& Methods}

\section{Sample collection and morphological studies}

Fresh specimens were collected from Nonggang Nature Reserve of Guangxi Autonomous Region in China, on dead angiosperm trunks or twigs. The specimens are deposited at the Herbarium of Guangxi University (GXU). The description of macroscopic characters was based on both fresh and dried specimens. The microscopic procedure followed Dai (2010). In elaborating the variation in the size of the spores, $5 \%$ of measurements were excluded from each end of the range, and were given in parentheses. Following were the abbreviations used in text: IKI = Melzer's reagent, $\mathrm{IKI}-=$ negative in Melzer's reagent, $\mathrm{KOH}=5 \%$ potassium hydroxide, $\mathrm{CB}=$ Cotton Blue, $\mathrm{CB}+=$ cyanophilous, $\mathrm{CB}^{-}=$acyanophilous, $\mathrm{L}=$ mean spore length (arithmetic average of all spores), $\mathrm{W}=$ mean spore width (arithmetic average of all spores), $\mathrm{Q}=$ variation in the $\mathrm{L} / \mathrm{W}$ ratios between the specimens studied, $\mathrm{n}=$ number of spores measured from given number of specimens. Sections were studied at magnification up to $\times 1500$ using a Nikon Eclipse $80 \mathrm{i}$ microscope and phase contrast illumination microscopy.

\section{DNA extraction, PCR amplification and sequencing}

DNA was extracted from dry material according to conventional CTAB procedure. Nuclear ITS and nLSU regions were amplified with the primer ITS5 and ITS4 (White et al. 1990), and LR0R and LR5 (Vilgalys \& Hester 1990) respectively. The PCR procedure was followed as: initial denaturation at $94{ }^{\circ} \mathrm{C}$ for $5 \mathrm{~min}$, followed by 30 cycles at $94{ }^{\circ} \mathrm{C}$ for $40 \mathrm{~s}, 56{ }^{\circ} \mathrm{C}$ for $40 \mathrm{~s}$ and $72{ }^{\circ} \mathrm{C}$ for $1 \mathrm{~min}$, and a final extension of $72{ }^{\circ} \mathrm{C}$ for $10 \mathrm{~min}$. The PCR products were directly purified and sequenced by Beijing Genomics Institute (BGI) with the same primers. Newly generated sequences from this study were submitted to GenBank. Except sequences obtained from this study, reference taxa were used for phylogenetic analysis through searching in GenBank (Table 1, 2).

\section{Phylogenetic analyses}

Sequence datasets of the ITS and nLSU were aligned with MEGA 5.2 (Tamura et al. 2011) and Clustalx1.83 (Thompson et al. 1997), then performed by SequenceMatrix-Windows-1.7.8 (Vaidya et al. 2011) to obtain their combined dataset sequences. Sequence alignment was deposited at TreeBASE (Perenniporia nonggangensis: http:/purl.org/phylo/treebase/phylows/study/TB2:S18433; Aporpium obtusisporum: 
http://purl.org/phylo/treebase/phylows/study/TB2:S20644) and was executed by PAUP* version 4.0b10 (Swofford 2002), MrMtgui 1.01 (http://www.genedrift.org/mtgui.php) and MrModeltest 2.3 (Nylander 2004, Posada \& Crandall 1998) to find the best-fit model.

Table 1 A list of species, specimens and GenBank accession number of sequences used in the study on Perenniporia nonggangensis.

\begin{tabular}{|c|c|c|c|}
\hline \multirow[b]{2}{*}{ Fungal taxon } & \multirow[b]{2}{*}{ Specimen numbers } & \multicolumn{2}{|c|}{ GenBank numbers } \\
\hline & & ITS & LSU \\
\hline Abundisporus sclerosetosus & MUCL 41438 & NR111366 & NG042479 \\
\hline Abundisporus violaceus & MUCL 38617 & FJ411100 & FJ393867 \\
\hline Donkioporia expansa & MUCL 35116 & FJ411104 & FJ393872 \\
\hline Perenniporia aridula & Dai 12398 & JQ001855 & JQ001847 \\
\hline Perenniporia bannaensis & Cui 8560 & JQ291727 & JQ291729 \\
\hline Perenniporia bannaensis & Cui 8562 & JQ291728 & JQ291730 \\
\hline Perenniporia contraria & Knudsen 04-111 & JQ861737 & JQ861755 \\
\hline Perenniporia detrita & MUCL 42649 & FJ411099 & FJ393866 \\
\hline Perenniporia fergusii & Gilbterson 16116 & HQ876607 & JF706337 \\
\hline Perenniporia formosana & Dai 5245 & HQ876612 & JX941590 \\
\hline Perenniporia fraxinea & Cui 7154 & HQ654095 & HQ654110 \\
\hline Perenniporia hainaniana & Cui 6364 & JQ861743 & JQ861759 \\
\hline Perenniporia japonica & Cui 7047 & HQ654097 & HQ654111 \\
\hline Perenniporia japonica & Cui 9181 & JQ001856 & JX141468 \\
\hline Perenniporia koreana & KUC20080517-15 & KJ156309 & KJ156301 \\
\hline Perenniporia lacerata & Cui 7220 & JX141448 & JX141458 \\
\hline Perenniporia luteola & Harkonen $1308 b$ & JX141457 & JX141467 \\
\hline Perenniporia maackiae & Cui 5605 & JN048760 & JN048780 \\
\hline Perenniporia macropora & Zhou 280 & JQ861748 & JQ861764 \\
\hline Perenniporia medulla-panis & MUCL 43250 & FJ411087 & FJ393875 \\
\hline Perenniporia minor & Cui 5782 & HQ883475 & HQ654115 \\
\hline Perenniporia nanlingensis & Cui 7589 & HQ848478 & HQ848487 \\
\hline Perenniporia nanlingensis & Cui 7620 & HQ848477 & HQ848486 \\
\hline Perenniporia narymica & Dai 10510 & HQ654101 & JF706346 \\
\hline Perenniporia nonggangensis & GXU 2098 & KT894732 & KT894733 \\
\hline Perenniporia ochroleuca & MUCL 39563 & FJ411097 & FJ393864 \\
\hline Perenniporia ohiensis & MUCL 41036 & FJ411096 & FJ393863 \\
\hline Perenniporia piceicola & Cui 10460 & JQ861742 & JQ861758 \\
\hline Perenniporia piceicola & Dai 4184 & JF706328 & JF706336 \\
\hline Perenniporia pyricola & Dai 10265 & JN048761 & JN048781 \\
\hline Perenniporia rhizomorpha & Cui 7507 & HQ654107 & HQ654117 \\
\hline Perenniporia robiniophila & Cui 7144 & HQ876608 & JF706341 \\
\hline Perenniporia russeimarginata & Yuan 1225 & JQ861749 & JQ861765 \\
\hline Perenniporia straminea & Cui 8858 & HQ654104 & JF706334 \\
\hline Perenniporia subacida & Dai 8224 & HQ876605 & JF713024 \\
\hline Perenniporia subacida & MUCL 31402 & FJ411103 & FJ393880 \\
\hline Perenniporia substraminea & Cui 10177 & JQ001852 & JQ001844 \\
\hline Perenniporia subtephropora & Dai 10962 & JQ861752 & JQ861768 \\
\hline Perenniporia tenuis & Wei 2783 & JQ001858 & JQ001848 \\
\hline Perenniporia tephropora & Cui 6331 & HQ848473 & HQ848484 \\
\hline Perenniporia tianmuensis & Cui 2648 & JX141453 & JX141463 \\
\hline Perenniporia tibetica & Cui 9457 & JF706326 & JF706332 \\
\hline Perenniporia truncatospora & Cui 6987 & JN048778 & HQ654112 \\
\hline Perenniporia vicina & MUCL 44779 & FJ411095 & FJ393862 \\
\hline
\end{tabular}


Table 1 Continued.

\begin{tabular}{llll}
\hline & & \multicolumn{2}{c}{ GenBank numbers } \\
\cline { 3 - 4 } Fungal taxon & Specimen numbers & ITS & LSU \\
\hline Perenniporiella chaquenia & MUCL 47647 & FJ411083 & FJ393855 \\
Perenniporiella micropora & MUCL 43581 & FJ411086 & FJ393858 \\
Pyrofomes demidoffii & MUCL 41034 & FJ411105 & FJ393873 \\
\hline
\end{tabular}

MrBayesian analysis of Perenniporia nonggangensis was performed by MrBayes 3.2.3 (Ronquist et al. 2012) with 200000 generations, and its estimate maximum likelihood phylogenies was performed by PhyML 3.1 (Guindon \& Gascuel 2003), which parameters of the model were as follows: tree topology search $=$ SPRs, initial tree $=$ BioNJ, model of nucleotides substitution $=$ Custom, other parameters came from the best-fit model.

MrBayesian analyses of Aporpium obtusisporum were performed by MrBayes 3.2.3 (Ronquist et al. 2012) with 300000 generations, and maximum parsimony analyses were performed in PAUP* version 4.0a151 (Swofford 2002) using tree-bisection reconnection (TBR) branchswapping algorithm, clade robustness was assessed using a bootstrap (BT) analysis with 1000 replicates. All phylogenetic trees were edited by TreeGraph 2.3.0-425 beta (Stöver \& Müller 2010).

Table 2 A list of species, specimens and GenBank accession number of sequences used in the study on Aporpium obtusisporum

\begin{tabular}{llll}
\hline & & \multicolumn{2}{c}{ GenBank nunbers } \\
\cline { 2 - 4 } Fungal taxon & Specimen no. & ITS & nLSU \\
\hline Aporpium caryae & WD2207 & AB871751 & AB871730 \\
Aporpium hexagonoides & ML297 & AB871754 & AB871735 \\
Aporpium hexagonoides & TFM F-27498 & AB871755 & AB871736 \\
Aporpium hexagonoides & Wei 5584 & JQ764667 & JQ764645 \\
Aporpium hexagonoides & Wei 5680 & JQ764668 & JQ764646 \\
Aporpium obtusisporum & GXU 2084 & KY655346 & KY655347 \\
Aporpium obtusisporum & GXU 2237 & KY655348 & KY655349 \\
Aporpium strigosum & TFM F-27651 & AB871757 & AB871738 \\
Aporpium strigosum & TUFC14542 & AB871760 & AB871741 \\
Aporpium strigosum & TUFC10589 & AB871756 & AB871737 \\
Aporpium strigosum & WD1710 & AB871759 & AB871740 \\
Aporpium strigosum & WD680 & AB871758 & AB871739 \\
Aporpium strigosum & Wei 5621 & JQ764659 & JQ764634 \\
Aporpium strigosum & Wei 5990 & JQ764660 & JQ764635 \\
Auricularia villosula & Cui 8688 & KM396810 & KM396858 \\
Auricularia villosula & HMAS 130446 & KM396817 & KM396864 \\
Elmerina caryae & Dai 3952 & JQ764651 & JQ764630 \\
Elmerina caryae & Dai 4549 & JQ764652 & JQ764631 \\
Elmerina dimidiata & O 18238 & JQ764663 & JQ764640 \\
Elmerina dimidiata & O 18261 & JQ764664 & JQ764641 \\
Elmerina efibulata & Dai 9322 & JQ764669 & JQ764647 \\
(=Protomerulius efibulatu) & & & \\
Elmerina foliacea & Yuan 5691 & JQ764666 & JQ764644 \\
(=Protodaedalea foliacea $)$ & & & \\
Exidia recisa & MW 315 & AF291276 & AF291322 \\
Exidia saccharina & RoKi 88 & AF291277 & AF291323 \\
Protodaedalea hispida & E701 & AB871767 & AB871748 \\
Protodaedalea hispida & WD548 & AB871768 & AB871749 \\
\hline & & & \\
\hline
\end{tabular}




\section{Results}

\section{Phylogeny of Perenniporia nonggangensis}

The combined ITS + nLSU dataset included sequences from 47 fungal specimens representing 42 taxa. The dataset had an aligned length of 1643 characters including gaps in the dataset (706 characters for ITS, 927 characters for nLSU), Pyrofomes demidoffii (Lév.) Kotl. \& Pouzar (MUCL 41034) and Donkioporia expansa (Desm.) Kotl. \& Pouzar (MUCL 35116) were used as outgroups. Best model for the ITS + nLSU dataset estimated and applied in the Bayesian analysis: GTR $+\mathrm{I}+\mathrm{G}$, lset nst $=6$, rates $=$ invgamma; prset statefreqpr $=\operatorname{dirichlet}(1,1,1,1)$. The average standard deviation of split frequencies of Bayesian analysis was 0.005698 . The parameters of the maximum likelihood phylogenetic model: Gamma shape parameter $=0.536$, Proportion of invariant $=0.370$, Nucleotides frequencies of $\mathrm{f}(\mathrm{A})=0.2433, \mathrm{f}(\mathrm{C})=0.2123, \mathrm{f}(\mathrm{G})=0.2696, \mathrm{f}(\mathrm{T})=$ 0.2748 . The phylogenetic tree topology of the estimated maximum likelihood tree was the same as the tree from Bayesian analysis (Fig. 1).

\section{Phylogeny of Aporpium obtusisporum}

The combined ITS + nLSU dataset included sequences from 26 fungal specimens representing 10 taxa. There were 1095 total characters ( 530 characters for ITS, 565 characters for nLSU) in the alignment, of which, 798 characters were constant, 65 were variable and parsimony-uninformative, and 232 were parsimony informative. The consensus tree was shown in Fig. 2 ( TL $=522, \mathrm{CI}=$ $0.736, \mathrm{RI}=0.863, \mathrm{RC}=0.635, \mathrm{HI}=0.264)$. Best model for the ITS $+\mathrm{nLSU}$ dataset estimated and applied in the Bayesian analysis: $\mathrm{SYM}+\mathrm{I}+\mathrm{G}$, Lset nst $=6$ rates $=$ invgamma; Prset statefreqpr $=$ fixed (equal). The average standard deviation of split frequencies of Bayesian analysis was 0.006729 . Tree topology of the maximum parsimony analysis showed similar to the tree from Bayesian analysis (Fig. 2).

\section{Taxonomy}

Perenniporia nonggangensis F.C. Huang \& Bin Liu, sp. nov.

Figs 3-5

MycoBank number: MB816217; Facesoffungi number: FOF03876

Holotype - CHINA, Guangxi, Chongzuo, Nonggang Nature Reserve, on fallen angiosperm trunk, July 11, 2014, GXU 2098 (Holotype).

Etymology - Nonggangensis (Lat.), referring to the locality of the type specimen.

Basidiocarps annual, resupinate to effused-reflexed, separable, soft and leathery when fresh, becoming corky upon drying, up to $35 \mathrm{~cm}$ long, $14 \mathrm{~cm}$ wide and $2.0 \mathrm{~cm}$ thick when resupinate; Pore surface cream to greyish cream when fresh, pale yellow-orange, capucine buff to sudan brown when dry (Ridgway 1912), the bruised part becoming brownish dark upon drying, some small pilei projecting on the edge of mature basidiocarps. Sterile margin white to cream, finely velutinate, sometimes radially fimbriate, up to $2.1 \mathrm{~cm}$ wide; pores round, angular, 4-5 per $\mathrm{mm}$; dissepiments thin, entire to lacerate; subiculum white to cream when fresh, white to capucine buff when dry, up to $1.4 \mathrm{~cm}$ thick. Tubes concolorous with pore surface, corky, up to $6 \mathrm{~mm}$ long. Hyphal system dimitic; generative hyphae with clamp connections; skeleto-binding hyphae dextrinoid and cyanophilous; tissues changed to dark brown in $\mathrm{KOH}$. Contextual generative hyphae frequent, 1.9$7.4 \mu \mathrm{m}$ diam, thin- to thick-walled, limited branched with clamp connections, generative hyphae common, tightly interwoven. Contextual skeleto-binding hyphae dominant, thick-walled with a wide to narrow lumen, or subsolid, limited branched, interwoven, 2.0-4.5 $\mu \mathrm{m}$ diam. Tramal generative hyphae frequent, 1.7-3.1 $\mu \mathrm{m}$ diam, thin-walled, limited branched with clamp connections, parts of generative hyphae tightly interwoven. Tramal skeleto-binding hyphae frequent, thick-walled, with a wide to narrow lumen, or subsolid, limited branched, interwoven, 1.7-3.6 $\mu \mathrm{m}$ diam. Cystidia absent; cystidioles fusoid, hyaline, thin-walled, 12.9-25.7 × 3.3-6.6 $\mu \mathrm{m}$; basidia clavate to barrel-shaped, with four sterigmata and a basal clamp connection, 8.7-18.1 $\times$ 3.9-7.1 $\mu \mathrm{m}$; basidioles oblong-ellipsoid to barrel-shaped, 7.9-15.9 $\times 4.4-7.6 \mu \mathrm{m}$. Basidiospores 


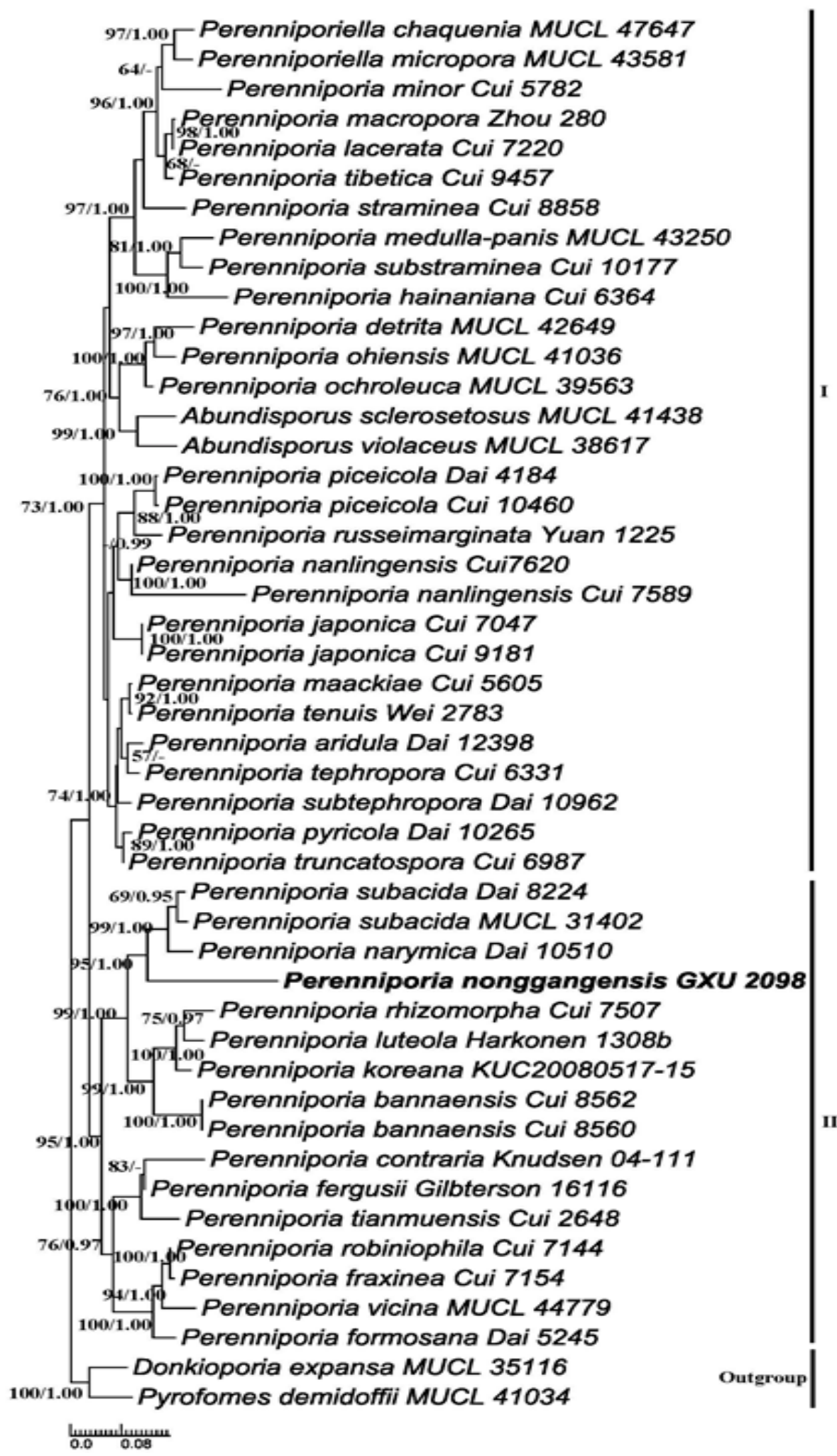

Figure 1 - The phylogenetic tree was generated by Maximum Likelihood method based on combined ITS + nLSU sequences. Bootstrap values (before the/) higher than $50 \%$ and Bayesian posterior probabilities (after the/) more than 0.95 were indicated along branches. 


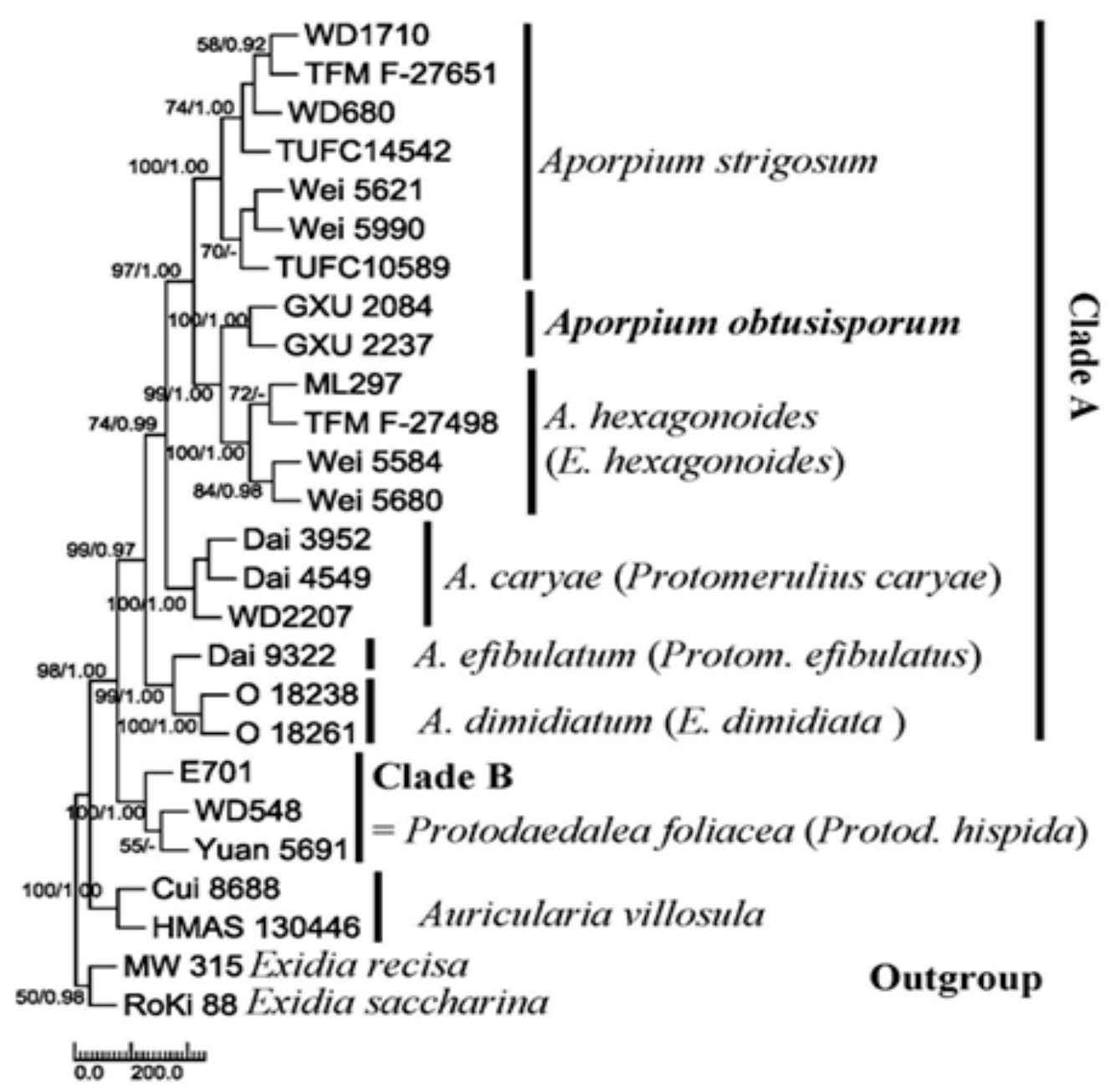

Figure 2 - The phylogenetic tree was generated by maximum parsimony analyses based on the combined ITS + nLSU dataset. Bootstrap values (before the/) higher than $50 \%$ and Bayesian posterior probabilities (after the/) more than 0.80 were indicated along branches.

broad-ellipsoid to subglobose, hyaline, thick-walled, smooth, occasionally with a large guttule, IKI-, slightly CB+, (2.9-)3.1-4.4(-5.1) × (2.6-)2.7-3.6(-3.9) $\mu \mathrm{m}, \mathrm{L}=3.79 \mu \mathrm{m}, \mathrm{W}=3.12 \mu \mathrm{m}, \mathrm{Q}$ $=1.21(\mathrm{n}=60)$.

Notes - Perenniporia nonggangensis differs from other Perenniporia species by resupinate to effused-reflexed basidiocarps with cream to greyish fresh pore, thick subiculum up to $1.4 \mathrm{~cm}$, a dimitic hyphal system with dextrinoid and cyanophilous skeleto-binding hyphae, the presence of long fusoid cystidioles, IKI-, slightly cyanophilous, and broad-ellipsoid to subglobose basidiospores.

Aporpium obtusisporum F.C. Huang \& Bin Liu, sp. nov.

Figs 6-7

MycoBank number: MB820107; Facesoffungi number: FOF03877

Etymology - Obtusisporum (Lat.), referring to the basidiospores obtuse apically.

Holotype - CHINA, Guangxi, Chongzuo, Nonggang Nature Reserve, on fallen angiosperm trunks or twigs, July 10, 2014, GXU 2084 (Holotype)

Basidiocarps annual, pileate, leathery, without odor; pilei projecting up to $8.3 \mathrm{~cm}, 11.3 \mathrm{~cm}$ wide and $4.0 \mathrm{~mm}$ thick at base, margin acute, entire, frequently incurved when dry, occasionally several pilei fused along theadjacent margins. Pilei spathulate or flabellate, bearing an elongated strap-like attachment base; upper surface from pale ochraceous buff to white toward the margin when fresh, salmon-buff, salmon to liver brown (Ridgway 1912) when dry, indistinctly concentrically zonate when fresh but distinct when dry, longitudinal stripes present, hyphal pegs 


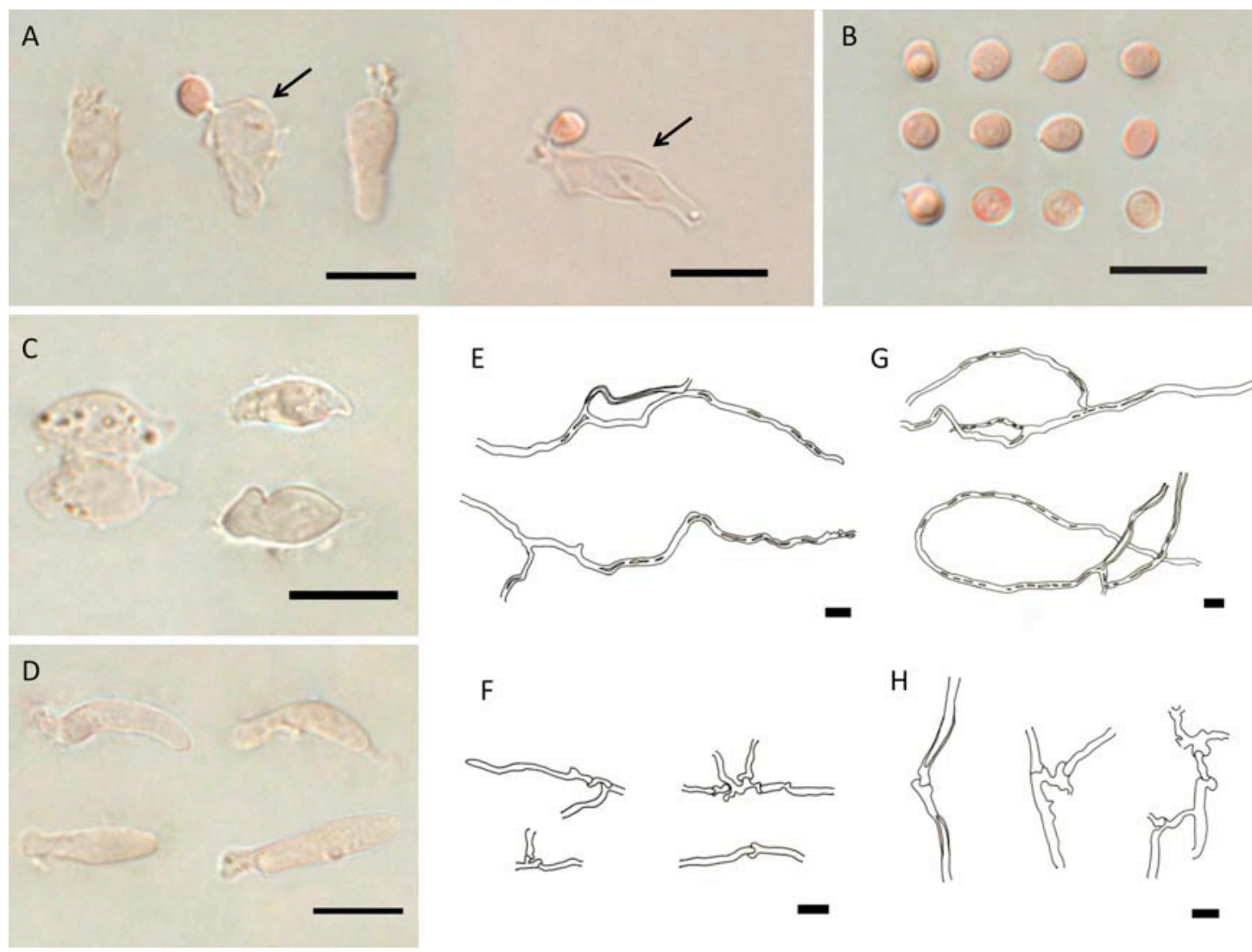

Figure 3 - Anatomical details of Perenniporia nonggangensis A: Basidia; B: Basidiospores; C: Basidioles; D: Cystidioles; E: Skeleto-binding hyphae from tube trama; F: Generative hyphae from tube trama; G: Skeleto-binding hyphae from subiculum; H: Generative hyphae from subiculum. Scale bars: $\mathrm{A}-\mathrm{H}=10 \mu \mathrm{m}$.

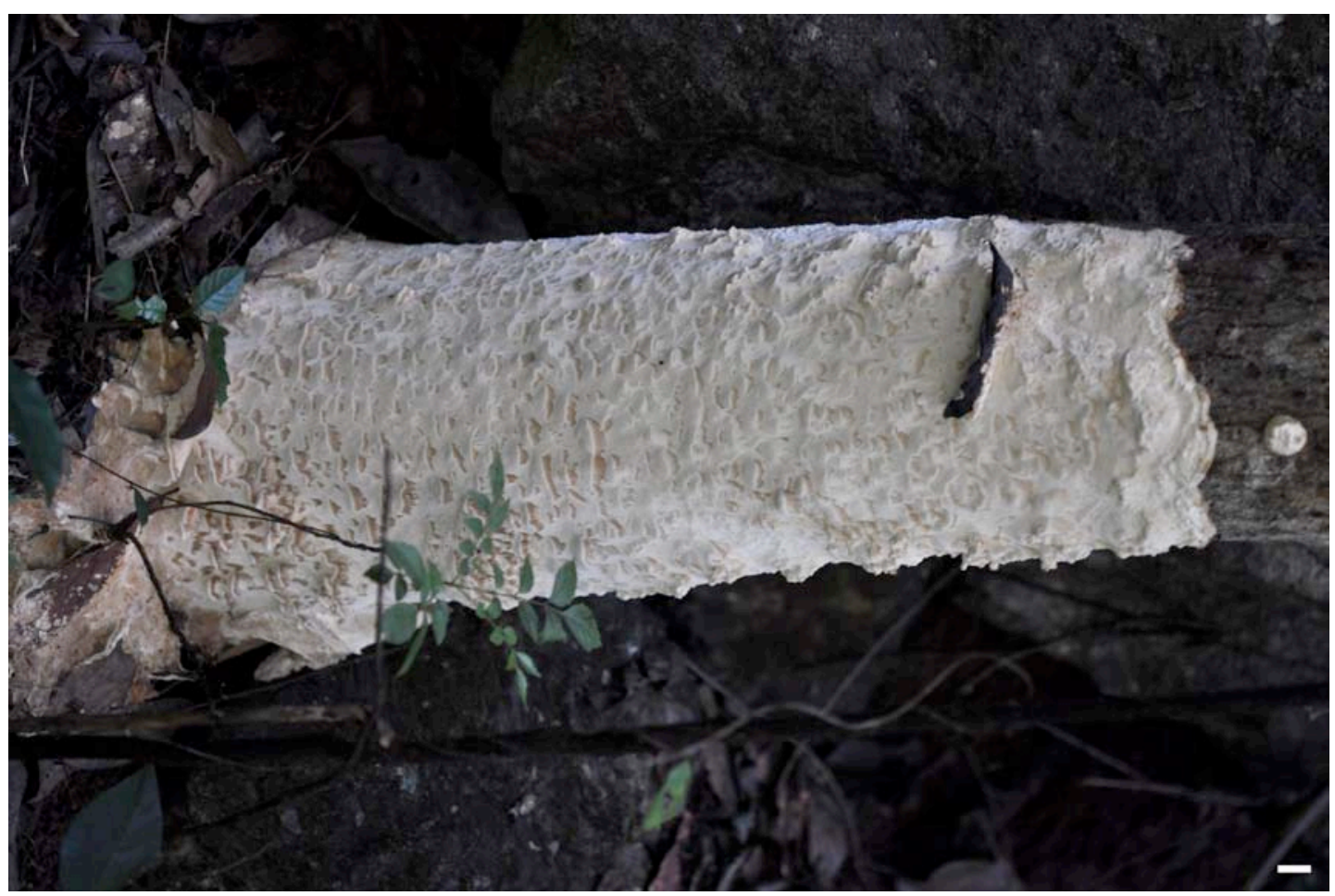

Figure 4 - A fresh basidiocarp of Perenniporia nonggangensis. Scale bars: $1 \mathrm{~cm}$. 

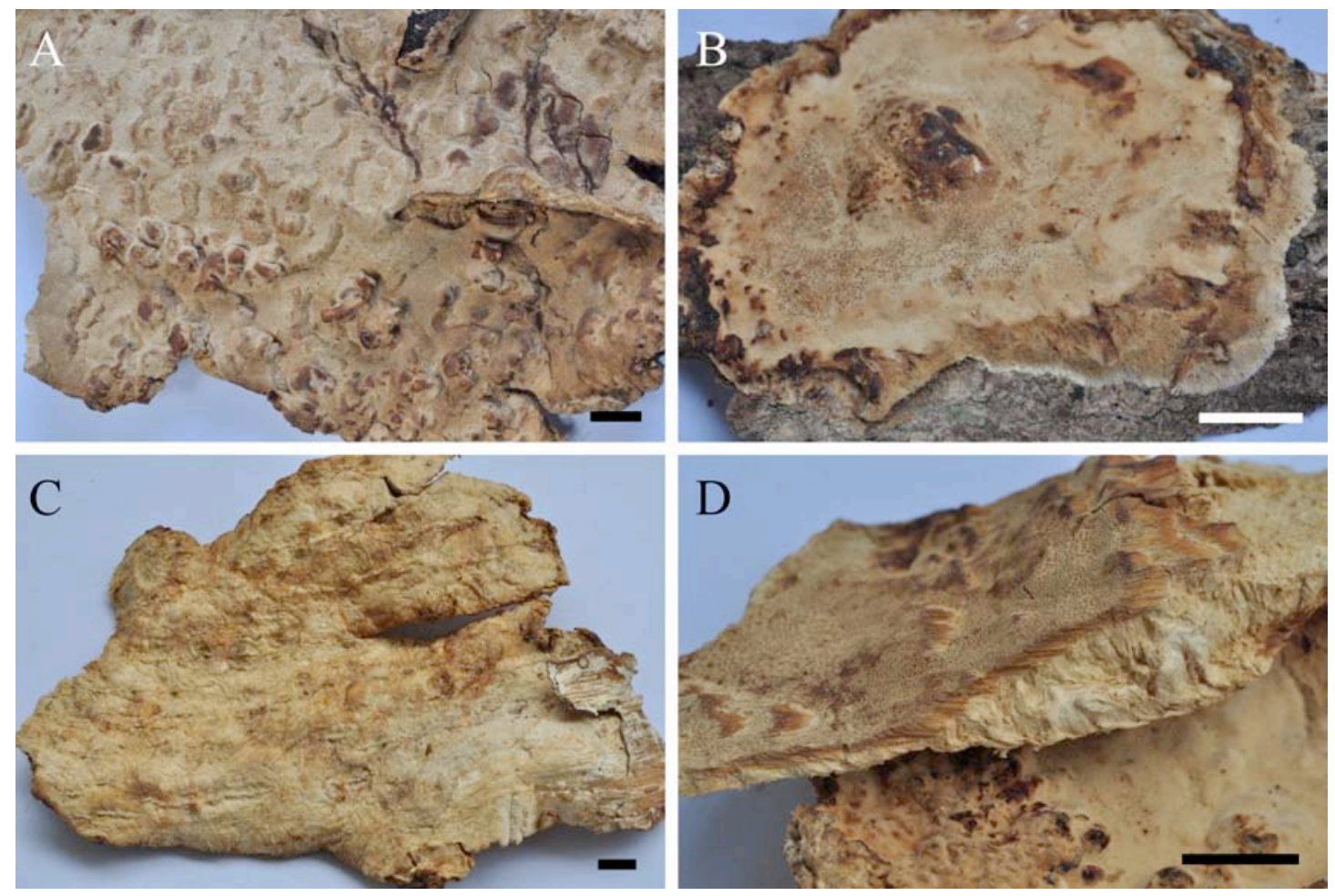

Figure 5 - Dry basidiocarps of Perenniporia nonggangensis A: part of the fruiting body; B: a juvenile basidiocarp with radially fimbriate margin; $\mathrm{C}$ : back surface of fruiting body; D: Context. Scale bars: $\mathrm{A}-\mathrm{D}=1 \mathrm{~cm}$.

abundant on pileal surface. Pore surface from pale ochraceous buff to white toward the margin when fresh, and salmon color to buckthorn brown or liver brown when dried, sterile margin lacking; pores angular, hexagonal, $0.5-2.5 \mathrm{~mm}$ in diam, or radially elongate when juvenile, and hymenophore poroid to lamellate when mature; thin dissepiments often bearing densely hyphal pegs. Subiculum white to pale ochraceous buff when fresh, and light ochraceous salmon to liver brown, rigid and leathery when dried, up to $2 \mathrm{~mm}$ thick. Tubes concolorous with pore surface, leathery, up to $2 \mathrm{~mm}$ long. Hyphal system dimitic; generative hyphae with clamp connections; skeletal hyphae IKI-, $\mathrm{CB}+$; tissues unchanged in $\mathrm{KOH}$. Contextual generative hyphae frequent, thin-walled, hyaline, with clamp-connections, moderately branched, 1.5-3.6 $\mu \mathrm{m}$ wide; contextual skeletal hyphae dominant, rarely branched, almost straight with a wide to narrow lumen or subsolid, 1.9-5.7 $\mu \mathrm{m}$ wide. Tramal generative hyphae frequent, thin-walled, hyaline, with clamp-connections, moderately branched, 1.5-3 $\mu \mathrm{m}$ wide; tramal skeletal hyphae rarely branched, almost straight, dominant, thick-walled with a wide to narrow lumen or subsolid, 2.3-4.6 $\mu \mathrm{m}$ wide. Hyphal pegs abundant in the hymenium, cylindrical, usually encrusted crystal, 46.4-131.8 $\times 13.2-41.9 \mu \mathrm{m}$. Cystidioles present, thin-walled, hyaline, more often fusoid, sometimes clavate, 7.4-24.3 $\times 2-5.2$ $\mu \mathrm{m}$. Basidia short clavate with a basal constriction, or barrel-shaped, cruciately septate in the apical portion, 11.6-29.9 × 5-8.8 $\mu \mathrm{m}$, four sterigmata up to $23.8 \mu \mathrm{m}$ long, basidioles aseptate, short clavate often with a basal constriction, or barrel-shaped, 9.6-22.6 $\times 4.2-8.6 \mu \mathrm{m}$. Basidiospores oval-elliptic, obtuse apically, smooth, hyaline, thin-walled, IKI-, CB+, (4.9-) 5.9-9.6 (-9.7) $\times$ (3.2-) 3.5-5.5 (-6.2) $\mu \mathrm{m}, \mathrm{L}=7.8 \mu \mathrm{m}, \mathrm{W}=4.7 \mu \mathrm{m}, \mathrm{Q}=1.66(\mathrm{n}=62)$.

Other materials examined (paratypes) - CHINA, Guangxi, Chongzuo, Nonggang Nature Reserve, on fallen angiosperm trunks or twigs, June 20, 2012, GXU 0489; July 19, 2012, GXU 0584; July 10, 2016, GXU 2237.

Notes - Aporpium obtusisporum was confirmed as a novel species based on morphological and phylogenetic supports. It differres from Aporpium hexagonoides by pileal surface covered by abundant hyphal pegs, hymenophore poroid to lamellate when mature. Basidiospores are shorter in average, cystidioles present and without dendrohyphidia. 


\section{Discussion}

The phylogeny of Perenniporia nonggangensis (Fig. 1) based on the combined ITS + nLSU formed a well supported lineage; species in the phylogeny included two groups (I and II). The relationships among species in our analysis are similar to those of Jang et al. (2015), but slightly different from those of Zhao \& Cui (2013) and Zhao et al. (2013a). Group I included species with typically truncate basidiospores, and group II included the non-truncate basidiospore species, such as Perenniporia luteola B.K. Cui \& C.L. Zhao, P. rhizomorpha B.K. Cui et al., and P. bannaensis B.K. Cui \& C.L. Zhao (except for P. fergusii Gilb. \& Ryvarden). Perenniporia nonggangensis clustered with $P$. subacida (Peck) Donk and P. narymica (Pilát) Pouzar with a high support (bootstrap values, $\mathrm{BP}=95$; Bayesian posterior probabilities, $\mathrm{BPP}=1.00$ ), and then these three taxa clustered with P. rhizomorpha, P. luteola, P. koreana Y. Jang \& J.J. Kim, and P. bannaensis in a clade also with high support $(\mathrm{BP}=99 ; \mathrm{BPP}=1.00)$.

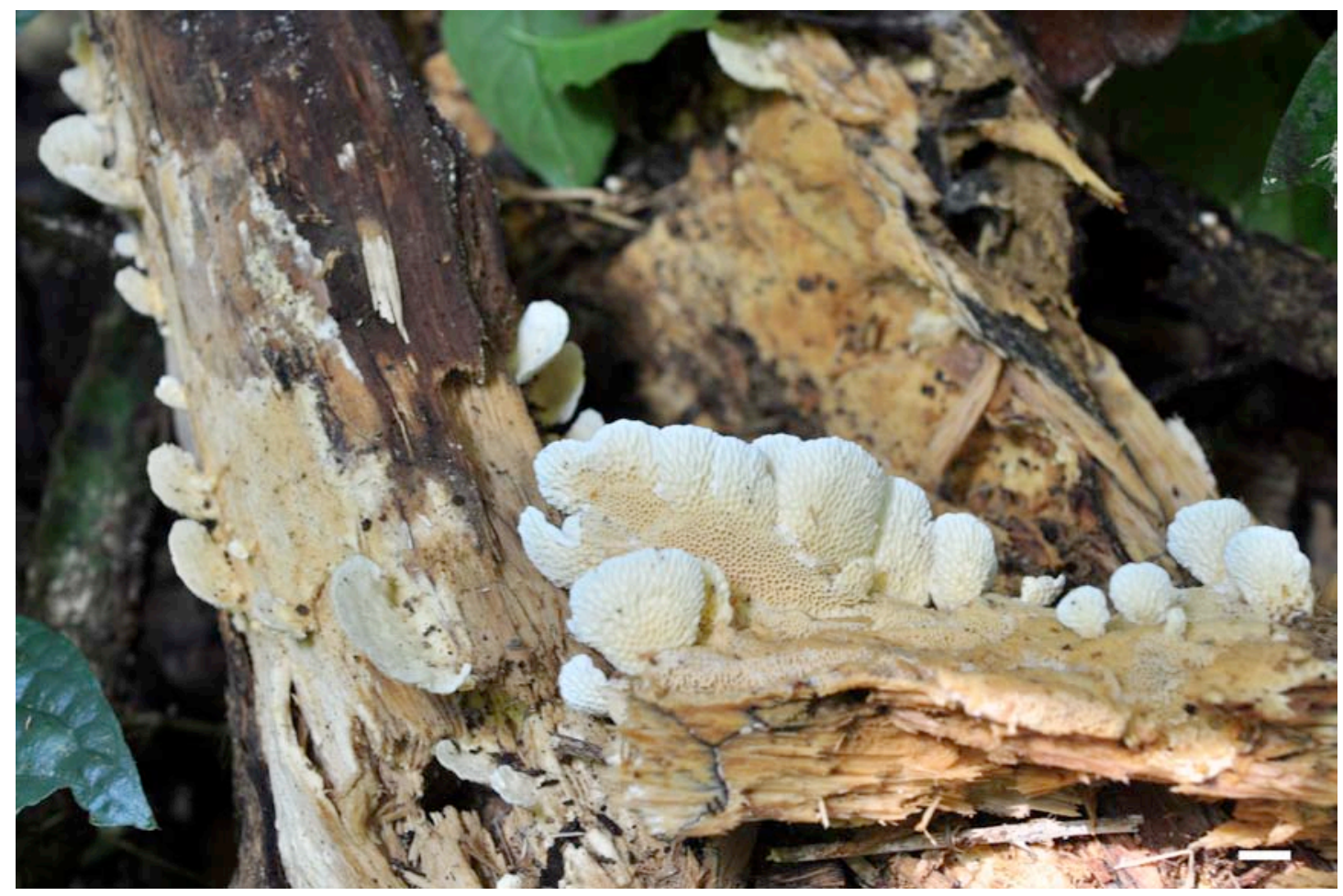

Figure 6 - Fresh basidiocarps of Aporpium obtusisporum. Scale bars: $1 \mathrm{~cm}$.

Perenniporia subacida is similar to P. nonggangensis by resupinate basidiocarp, dextrinoid and cyanophilous skeletal hyphae, fusoid cystidioles, and non-truncate, non-dextrinoid basidiospores (Ryvarden \& Gilbertson 1994, Zhao \& Cui 2013, Zhao et al. 2013b), while $P$. subacida differs in its cream to pale yellowish pore surface, tissues unchanged in $\mathrm{KOH}$, rarely branched skeletal hyphae, and longer basidiospores $(4.3-5.4 \times 3.2-4.1 \mu \mathrm{m}$, Dai et al. 2002). Perenniporia narymica (Zhao et al. 2013b) is similar to P. nonggangensis by annual and resupinate basidiocarps, a dimitic hyphal system with clamped generative hyphae, fusoid cystidioles, and nontruncate, non-dextrinoid basidiospores. But it distinguishes from the latter by amyloid and acyanophilous skeletal hyphae which dissolved in $\mathrm{KOH}$, and cyanophilous basidiospores, and it was treated as an independent genus Yuchengia by Zhao et al. (2013b).

Morphologically, Perenniporia luteola, P. koreana and $P$. bannaensis are very similar to $P$. nonggangensis by sharing the similar characteristics of resupinate basidiocarps, dextrinoid and cyanophilous skeletal hyphae, fusoid cystidioles, and non-truncate basidiospores. But P. luteola differs from $P$. nonggangensis by buff to buff-yellow fresh pores, thin subiculum up to $0.5 \mathrm{~mm}$ thick, hyphae unchanged in $\mathrm{KOH}$, and bigger basidiospores $(6.1-6.9 \times 5.1-5.4 \mu \mathrm{m}$, Zhao \& Cui 2013). 


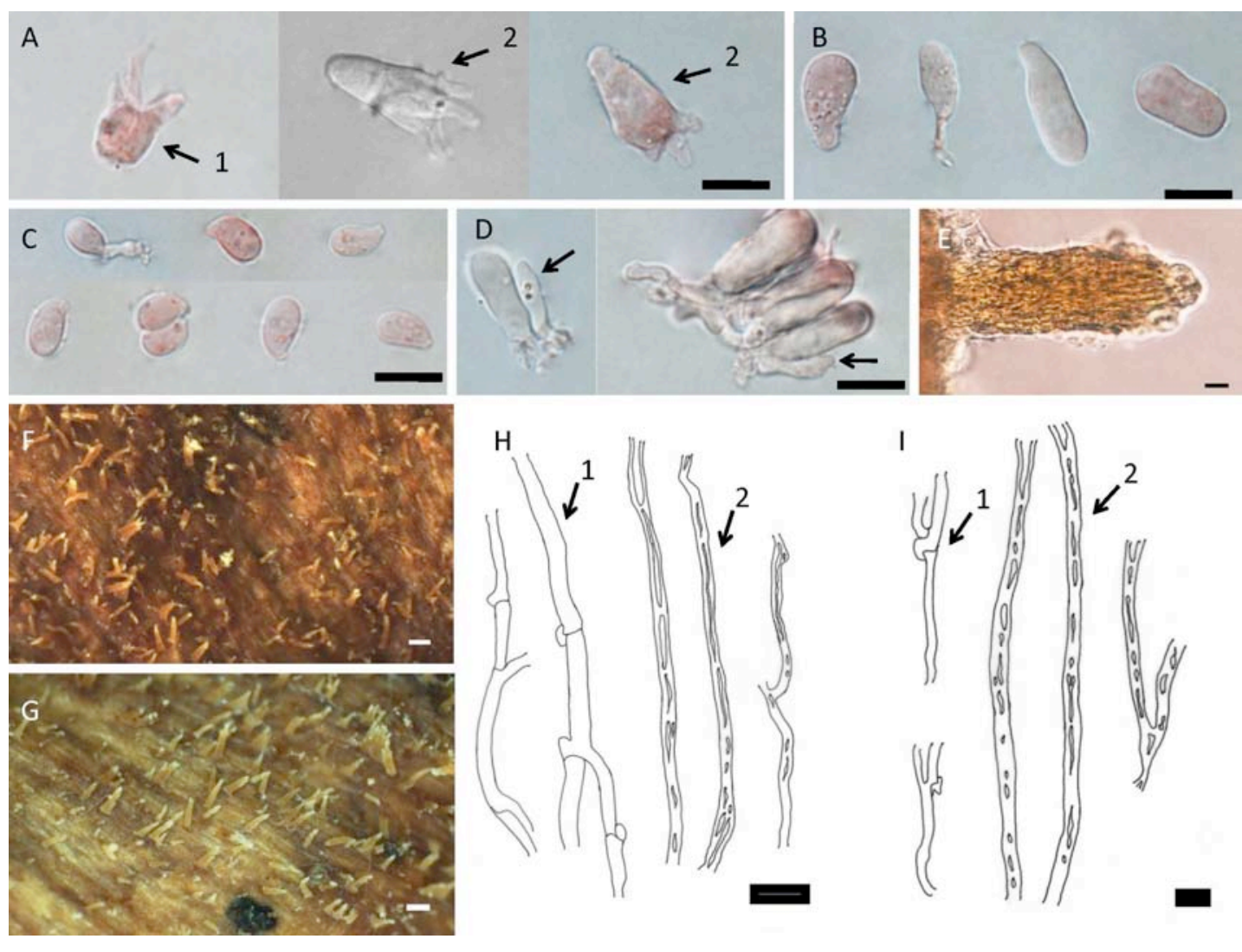

Figure 7 - Anatomical details of Aporpium obtusisporum A1: Epibasidium, A2: Basidia; B: Basidioles; C: Basidiospores; D: Cystidioles; E: Hyphal pegs from tubes; F, G: Hyphal pegs from pileal surface; H1: Generative hyphae from tube trama; H2: Skeletal hyphae from tube trama; I1: Generative hyphae from context; I2: Skeletal hyphae from context. Scale bars: A-I $=10 \mu \mathrm{m} ; \mathrm{F}, \mathrm{G}=$ $100 \mu \mathrm{m}$.

Perenniporia koreana distinguishes from $P$. nonggangensis by yellowish pores, rarely branched skeletal hyphae, dextrinoid, cyanophilous and bigger basidiospores $(6-7 \times 3.9-5.2 \mu \mathrm{m}$, Jang et al. 2015). Perenniporia bannaensis differs from P. nonggangensis by cream to buff fresh pores, thinner fruiting body up to $2 \mathrm{~mm}$ thick, smaller pores $(6-8$ per $\mathrm{mm})$, unbranched skeletal hyphae, longer and strongly dextrinoid basidiospores $(5.2-6 \times 4-4.6 \mu \mathrm{m}$, Zhao et al. 2013a).

Perenniporia rhizomorpha is also similar to $P$. nonggangensis by resupinate basidiocarps, dextrinoid and cyanophilous skeletal hyphae, and non-truncate basidiospores, but it is easy to distinguish from the latter by rhizomorphic basidiocarps, cream-buff to yellow-buff fresh pores, tissue unchanged in $\mathrm{KOH}$, skeletal hyphae usually encrusted with fine crystals, the absence of cystidioles, and bigger, dextrinoid, cyanophilous basidiospores $(5.3-6.5 \times 4.1-5.2 \mu \mathrm{m}$, Cui et al. 2007).

The phylogenetic tree of Aporpium obtusisporum (Fig. 2) based on the combined ITS + nLSU sequence also formed a well-supported lineage. The relationships among species in the phylogeny are similar to those of Sotome et al. (2014). Clade A included type species Aporpium caryae and other species also from the same genus, A. strigosum Sotome \& T. Hatt., A. obtusisporum, A. hexagonoides A. David \& Jaq., A. efibulatum (Y.C. Dai \& Y.L. Wei) Sotome \& T. Hatt. and A. dimidiatum A. David; however, the species of clade B came from Protodaedalea, P. hispida Imazeki (Fig. 2). Moreover, the new species A. obtusisporum is genetically closely related to $A$. hexagonoides with strongly supported (bootstrap values, $\mathrm{BP}=99$; Bayesian posterior probabilities, $\mathrm{BPP}=1.00)$.

Morphologically, Aporpium obtusisporum is very similar to A. hexagonoides. Both species shared many similar features including the pileate basidiocarps, tubes densely covered with hyphal pegs, a dimitic hyphal system, epibasidia septate when mature. However, the latter was distinct 
from A. obtusisporum by hirsute pileal surface without hyphal pegs, white to cream fresh pore surface, angular to partly sinuous or elongated pores, longer basidiospores in average $(8-10 \times 4-5$ $\mu \mathrm{m}, \mathrm{L}=9.0 \mu \mathrm{m}$ ), the presence of dendrohyphidia (Sotome et al. 2014).

\section{Acknowledgements}

We thank Prof. Yu-Cheng Dai (BJFC, China) provided valuable comments and suggestions for improvement of the manuscript. This research was supported by Ministry of Science and Technology of China for Fundamental Research (2013FY110400), Project of Guangxi Innovation Team of National Modern Agricultural Industry System (nycytxgxcxtd-07-01) and Key Project of Nanning Science and Technology (No. 20146350).

\section{References}

Cui BK, Dai YC, Decock CA 2007 - A new species of Perenniporia (Basidiomycota, Aphyllophorales) from eastern China. Mycotaxon 99, 175-180.

Cui BK, Zhao CL 2012 - Morphological and molecular evidence for a new species of Perenniporia (Basidiomycota) from Tibet, southwestern. Mycoscience 53, 365-372.

Decock C, Ryvarden L 2015 - Studies in Perenniporia s.1. African taxa IX: Perenniporia vanhullii sp. nov. from open woodlands. Synopsis Fungorum 33, 44.

Decock C, Stalpers J 2006 - Studies in Perenniporia: Polyporus unitus, Boletus medulla-panis, the nomenclature of Perenniporia, Poria and Physisporus, and a note on European Perenniporia with a resupinate basidiome. Taxon 53, 759-778.

Dai YC 2010 - Hymenochaetaceae (Basidiomycota) in China. Fungal Diversity 45, 131-343.

Dai YC, Niemelä T, Kinnunen J 2002 - The polypore genera Abundisporus and Perenniporia (Basidiomycota) in China, with notes on Haploporus. Annales Botanici Fennici 39, 169-182.

Donk MA. 1960 - The generic names proposed for Polyporaceae. Persoonia 1, 173-302.

Guindon S, Gascuel O 2003 - A simple, fast and accurate algorithm to estimate large phylogenies by maximum likelihood. Systematic Biology 52, 696-704.

Jang Y, Jang S, Lim YW, Kim C, Kim JJ 2015 - Perenniporia koreana, a new wood-rotting basidiomycete from South Korea. Mycotaxon 130, 173-179.

Miettinen O, Spirin V, Niemelä T 2012 - Notes on the genus Aporpium (Auriculariales, Basidiomycota), with a new species from temperate Europe. Annales Botanici Fennici 49, 359-368.

Núñez M, Ryvarden L 2001 - East Asian polypores 2. Synopsis Fungorum 14, 170-522.

Nylander JAA 2004 - MrModeltest v2. Evolutionary Biology Center, Uppsala University, Uppsala, Sweden.

Posada D, Crandall KA 1998 - Modeltest: testing the model of DNA substitution. -Bioinformatics $14,817-818$.

Reid DA 1992 - The genus Elmerina (Tremellales) with accounts of two species from Queensland, Australia. Persoonia 14, 465-474.

Ridgway R 1912 - Color Standards and Color Nomenclature. United States National Museum, Washington, D.C.

Ronquist F, Teslenko M, Mark P van der, Ayres D, Darling A, Höhna S, Larget B, Liu L, Suchard MA, Huelsenbeck JP 2012 - MrBayes 3.2: Efficient Bayesian phylogenetic inference and model choice across a large model space. Systematic Biology 61, 539-542.

Ryvarden L 1991 - Genera of polypores, nomenclature and taxonomy. Synopsis Fungorum 5, 1363.

Ryvarden L, Gilbertson RL 1994 - European polypores. Part 2. Synopsis Fungorum 7, 394-743

Singer R 1944 - Notes on taxonomy and nomenclature of the polypores. Mycologia 36, 65-69. 
Sotome K, Maekawa N, Nakagiri A, Lee SS, Hattori T 2014 - Taxonomic study of Asian species of poroid Auriculariales. Mycological Progress 13, 987-997.

Stöver BC, Müller KF 2010 - TreeGraph 2: Combining and visualizing evidence from different phylogenetic analyses. -BMC Bioinformatics 11, 7.

Swofford DL 2002 - PAUP *, phylogenetic analysis using parsimony (*and other methods), ver. 4.0b10. - Sinauer Associates.

Tamura K, Peterson D, Peterson N, Stecher G, Nei M, Kumar S 2011 - MEGA5: Molecular evolutionary genetics analysis using maximum likelihood, evolutionary distance, and maximum parsimony methods. Molecular Biology and Evolution 28, 2731-2739.

Thompson JD, Gibson TJ, Plewnlak F, Jianmougin F, Higgins DG 1997 - The Clustal X windows interfaces: flexible strategies for multiple sequence alignment aided by quality analysis tools. Nucleic Acids Research 24, 4876-4882.

Vaidya G, Lohman DJ, Meier R 2011 - SequenceMatrix: concatenation software for the fast assembly of multi-gene datasets with character set and codon information. Cladistics 27, 171-180.

Vilgalys R, HesterM 1990 - Rapid genetic identification and mapping of enzymatically amplified ribosomal DNA from several Cryptococcus species. Journal of Bacteriology 172, 4238-4246.

White TJ, Bruns T, Lee S, Taylor J 1990 - Amplification and direct sequencing of fungal ribosomal RNA genes for phylogenies. In: Innis MA, Gelfand DH, Sninsky JJ, White TJ (eds) PCR protocols, a guide to methods and applications. Academic, San Diego

Wu F, Zhou LW, Yuan Y, Dai YC 2017 - Aporpium miniporum, a new polyporoid species with vertically septate basidia from southern China. Phytotxa (in press)

Yuan HS, Dai YC 2012 - A Wood-inhabiting fungi in southern China. 6. Polypores from Guangxi Autonomous Region. Annales Botanici Fennici 49:341-351.

Zhao CL, Cui BK 2013 - Three new Perenniporia (Polyporales, Basidiomycota) species from China based on morphological and molecular data. Mycoscience 54, 231-240.

Zhao CL, Cui BK, Dai YC 2013a - New species and phylogeny of Perenniporia based on morphological and molecular characters. Fungal Diversity 58, 47-60.

Zhao CL, Cui BK, Steffen KT 2013b - Yuchengia, a new polypore genus segregated from Perenniporia (Polyporales, Basidiomycota) based on morphological and molecular characters. Nordic Journal of Botany 31, 331-338.

Zhao CL, Shen LL, Cui BK 2014 - Perenniporia cinereofusca sp. nov. (Polyporales, Basidiomycota) evidenced by morphological characters and phylogenetic analyses. Mycoscience 55, 417-422. 